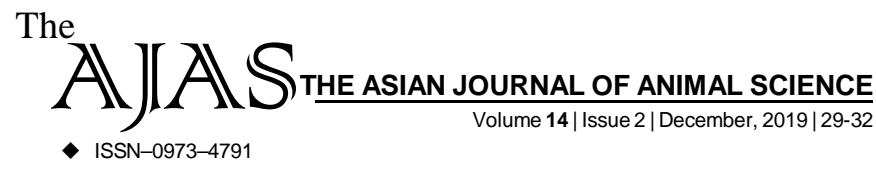

DOI : 10.15740/HAS/TAJAS/14.2/29-32 Visit us | www.researchjournal.co.in $\mathrm{S}$

RESEARCH ARTICLE.

\title{
To study the effect of supplementation of Chakka whey on growth performance of goat kids
}

D.M. Choudhari, S.D. Chavan, P.S. Umbarkar and V.S. Kadam

Author for Corresponding -

D.M. Choudhari Animal Husbandry and Dairy Science, Krishi Vigyan Kendra, Dhule (M.S.) India

Email. : balrajdairy_2007@ rediffmail.com
ABSTRACT...... A flock of 18 Osmanabadi goat' kids upto 1 week of age was selected and divided in to three groups on the basis of nearness of age and body weight of animal. Each group includes 6 goats and trial was carried out upto 90 days. Kids were divided into three groups and called with $\mathrm{T}_{1}$ (control, conventional method), $\mathrm{T}_{2}$ (Conventional method $90 \%+10$ $\%$ Chakka whey) and $\mathrm{T}_{3}$ (Conventional method $80 \%+20 \%$ Chakka whey) group i.e. Treatment $\mathrm{T}_{1}$ - whole goat milk; Treatment $\mathrm{T}_{2}-90$ per cent of goat milk and 10 per cent of Chakka whey; Treatment $\mathrm{T}_{3}-80$ per cent of goat milk and 20 per cent of Chakka whey, respectively. During experimental trial maximum growth rate (weight gains) was obtained by 20 per cent Chakka whey feeding to the growing goat kids. The cost of feeding is less in $\mathrm{T}_{3}$ (20\% Chakka whey) which can be beneficial to goat owner by getting higher monetary return by selling of animal due to higher growth rate and weight gain.

\section{KEY WORDS...... Whey, Kid, Goat, Feed}

HOW TO CITE THIS ARTICLE - Choudhari, D.M., Chavan, S.D., Umbarkar, P.S. and Kadam, V.S. (2019). To study the effect of supplementation of Chakka whey on growth performance of goat kids. Asian J. Animal Sci., 14(2): 29-32. DOI : 10.15740/HAS/TAJAS/14.2/29-32. Copyright@ 2019: HindAgri-Horticultural Society.

ARTICLE CHRONICLE - Received : 07.10.2019; Revised : 18.11.2019; Accepted : 16.11.2019 